\title{
Respiration and circulation affected by gas leakage into the abdominal cavity during endoscopic esophageal submucosal dissection after gastrostomy: a case report
}

\author{
Jun Honda ${ }^{*}\left(\mathbb{D}\right.$, Keisuke Kuwana', Saori Kase ${ }^{1}$, Shinju Obara² and Satoki Inoue ${ }^{1}$
}

\begin{abstract}
Background: Pneumoperitoneum is a common complication of percutaneous endoscopic gastrostomy (PEG). We report a case of circulatory and respiratory depression due to pneumoperitoneum caused by PEG dislodgement during endoscopic submucosal dissection (ESD) surgery.

Case presentation: A 46-year-old man with PEG for dysphagia underwent ESD for esophageal cancer under general anesthesia. The patient developed a gradual increase in peak inspiratory pressure, followed by a decrease in peripheral oxygen saturation $\left(\mathrm{SpO}_{2}\right)$ and blood pressure, as well as an increase in heart rate (HR) during endoscopic submucosal ESD for esophageal cancer. We suspected mediastinal emphysema due to esophageal perforation, but the surgery was successfully completed. Postoperative computed tomography (CT) revealed that the abdominal and gastric walls, which had been fixed by PEG, were detached, resulting in a large amount of intra-abdominal gas and mediastinal emphysema.
\end{abstract}

Conclusions: ESD in patients with PEG should be performed carefully because of the possibility of intraoperative PEG dislodgement and pneumoperitoneum caused by insufflation gas leakage.

Keywords: Percutaneous endoscopic gastrostomy, Endoscopic submucosal dissection, Pneumoperitoneum, Insufflation gas leakage

\section{Background}

Percutaneous endoscopic gastrostomy (PEG) has been a common method of mid- to long-term enteral nutrition since its introduction in 1980.

Pneumoperitoneum is a common complication of the PEG procedure and does not require intervention in the absence of clinical symptoms [1], but the incidence of pneumoperitoneum is as high as $50 \%$ after prolonged PEG [2]. The cause of pneumoperitoneum in PEG patients is thought to be air leakage, probably due

\footnotetext{
*Correspondence: j.honda1984@gmail.com

${ }^{1}$ Department of Anesthesiology, Fukushima Medical University Hospital,

1 Hikarigaoka, Fukushima 960-1295, Japan

Full list of author information is available at the end of the article
}

to inadequate fixation of the gastric wall [3]. In addition, when PEGs are dislodged, the anterior gastric wall and abdominal wall may separate, allowing gastric contents to leak into the abdominal cavity, resulting in peritonitis, which may require laparotomy [1].

In this report, we present a case of a PEG patient who underwent endoscopic submucosal dissection (ESD) under general anesthesia and experienced circulatory and respiratory depression due to accidental PEG bumper dislodgement and pneumoperitoneum, probably caused by insufflation gas leakage from the surgical field.

We obtained written informed consent from the patient to present this case. 


\section{Case presentation}

A 46-year-old man ( $185 \mathrm{~cm}$ in height, and $62 \mathrm{~kg}$ in weight) was scheduled for esophageal ESD under general anesthesia with tracheal intubation in the left lateral position. He had a history of radiochemotherapy for oropharyngeal cancer, and of PEG tube placement for dysphagia 6 month before (Fig. 1a). Anesthetic chart is shown in Fig. 2. General anesthesia was induced with propofol, remifentanil, and rocuronium followed by orotracheal intubation uneventfully. The ventilator was set in volumecontrolled ventilation mode $\left(\mathrm{FiO}_{2} 0.35\right.$, TV $500 \mathrm{ml}$, RR $11 / \mathrm{min}$, and PEEP $5 \mathrm{~cm} \mathrm{H}_{2} \mathrm{O}$ ). Gradual increase in peak inspiratory pressure occurred $60 \mathrm{~min}$ after starting surgery, which was increased from $18 \mathrm{~cm} \mathrm{H}_{2} \mathrm{O}$ to $28 \mathrm{~cm} \mathrm{H}_{2} \mathrm{O}$ in $30 \mathrm{~min}$. An abrupt increase of systolic blood pressure from 90 to $134 \mathrm{mmHg}$, followed by a decrease in peripheral oxygen saturation $\left(\mathrm{SpO}_{2}\right)$ from 100 to $82 \%$ occurred approximately $90 \mathrm{~min}$ after starting surgery. At this
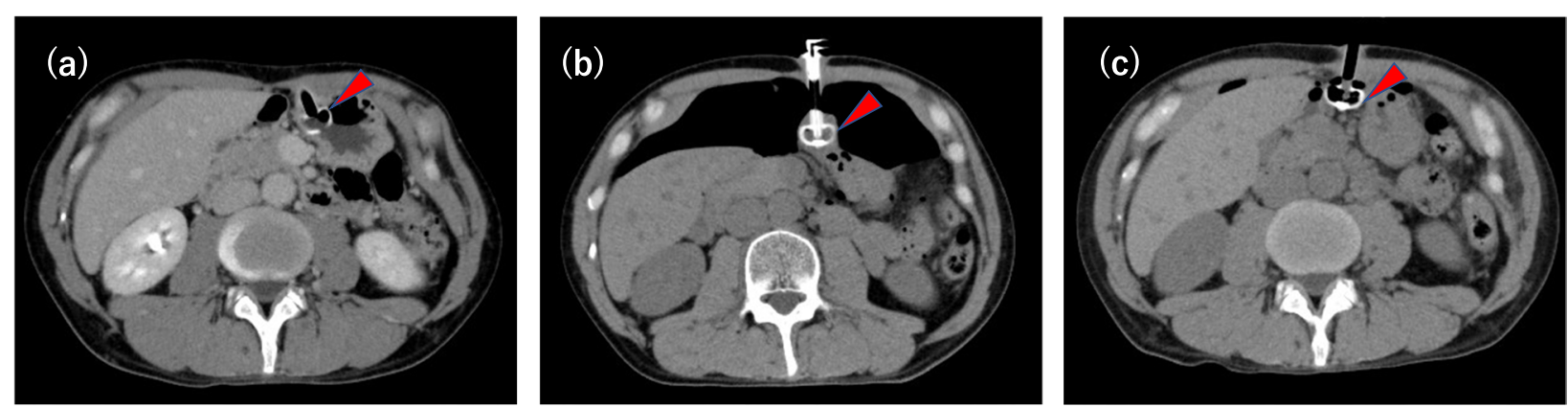

Fig. 1 Computed tomographic images. Preoperative computed tomographic scans (a) showed percutaneous endoscopic gastrostomy bumper (red arrow) fixing stomach properly. Postoperative computed tomographic scans (b) showed percutaneous endoscopic gastrostomy bumper (red arrow) dislodged from abdominal wall. Postoperative day 4 computed tomographic scans (c) showed percutaneous endoscopic gastrostomy bumper (red arrow) protrude from stomach

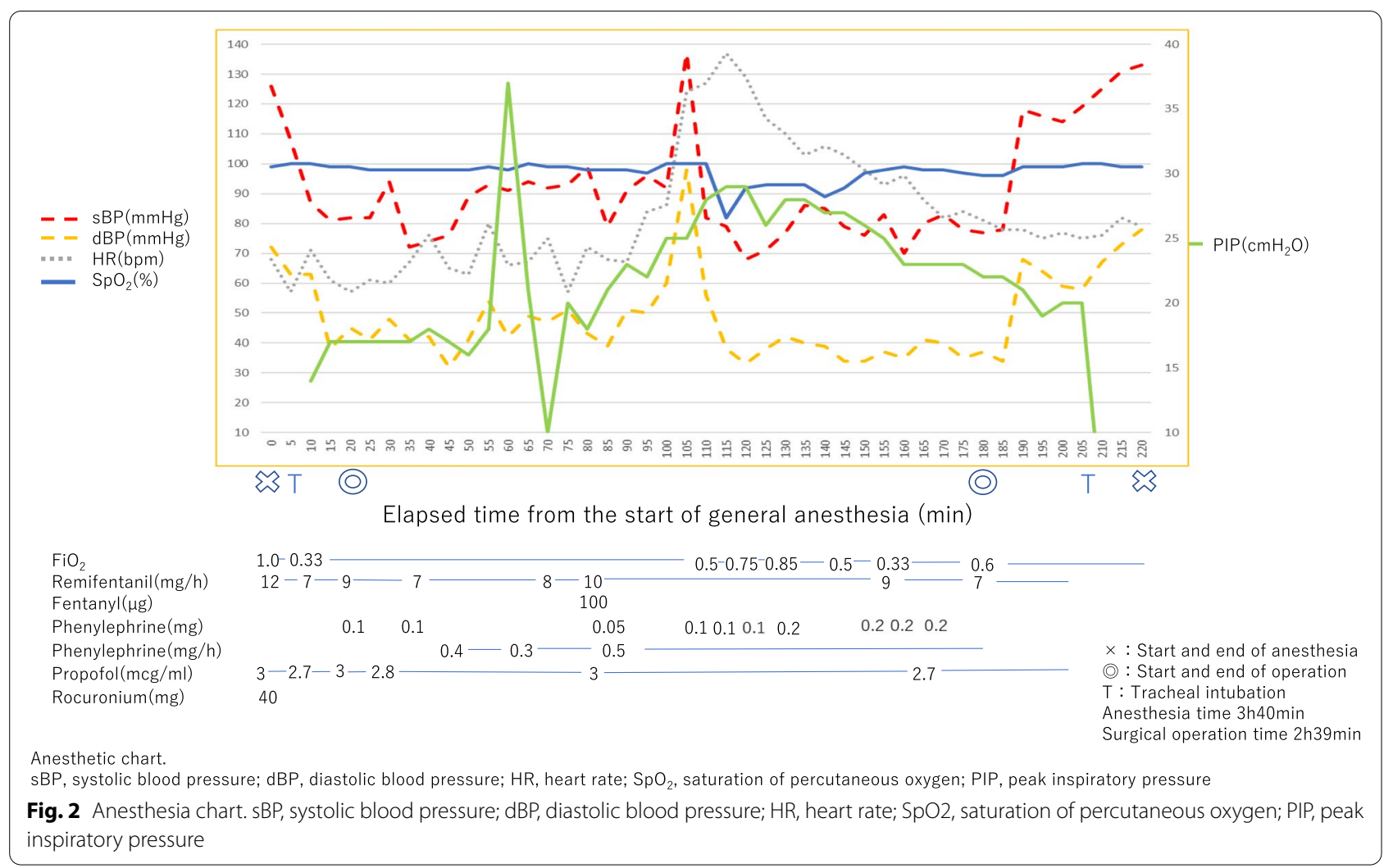


point, the surgeon told us that there was no possibility of esophageal perforation, but we suspected the possibility of mediastinal emphysema because of the subcutaneous emphysema in the anterior chest. $\mathrm{SpO}_{2}$ was increased to $92 \%$ and hemodynamic condition was subsided by increasing the inhalational oxygen concentration and the repeated dose of phenylephrine. Surgery completed successfully and the intubation tube was removed in the operating room. No intraoperative patient movement was observed. Postoperative computed tomography (CT) revealed pneumoperitoneum with dislodgement of the PEG tube (Figs. 1b, 3) After the PEG button was opened, the intra-abdominal gas decreased, but on the fourth postoperative day, the PEG bumper was dislodged from the stomach into the abdominal cavity and was removed (Fig. 1c). The fistula in the gastric wall closed spontaneously. Antibiotics were used to prevent intra-abdominal infection, and the patient was discharged 16days after surgery as there were no signs of infection.

\section{Discussion}

We reported pneumoperitoneum due to PEG bumper dislodgement during ESD in a PEG patient. We initially suspected mediastinal emphysema caused by esophageal perforation because of the sudden intraoperative changes in circulatory and respiratory status. However, postoperative CT showed PEG bumper dislodgement and a large amount of intra-abdominal gas accumulation. We concluded that it was highly likely that the insufflation gas in the surgical field had accumulated in the stomach, leaked into the abdominal cavity through the gastrostomy hole, and caused mediastinal emphysema via the esophageal hiatus. We believe that this increase in insufflation pressure may have exacerbated

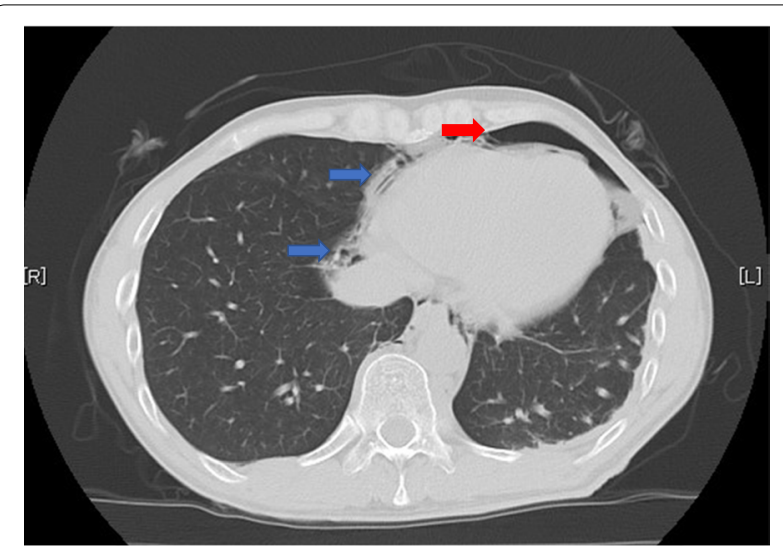

Fig. 3 Computed tomographic images. Thoracic computed tomography showing a left-sided pneumothorax (red arrow) and mediastinal emphysema (blue arrow) the patient's respiratory depression. Pneumoperitoneum is a complication that occurs in as many as $50 \%$ of patients after PEG placement [2], but to our knowledge, there are no reports of PEG bumper dislodgement and pneumoperitoneum during esophageal ESD in PEG patients. Complications arising from $\mathrm{CO} 2$ insufflation include pneumothorax, mediastinal emphysema, and subcutaneous emphysema [4]. Pathways of $\mathrm{CO} 2$ gas leakage from the abdominal cavity to the thoracic cavity include surgically induced medically induced fistulae and diaphragmatic anatomy (e.g., esophageal hiatus and vena caval foramen) [5].

In the case of laparoscopic surgery, factors that increase the likelihood of subcutaneous emphysema, pneumothorax, and mediastinal emphysema include the flow rate and pressure of the delivered gas, and the gas usage should be recorded [6].

Several improvements can be made: First, in endoscopic esophageal surgery, we believe that the flow rate and pressure of the insufflation gas as well as the amount of gas used should be recorded as in laparoscopic surgery, because in PEG patients, air accumulation in the stomach may cause the PEG bumper dislodgement, resulting in pneumoperitoneum.

Second, intraoperative measures such as keeping the PEG button open or inserting a tube for degassing from the PEG may be useful to prevent PEG bumper dislodgement by reducing the increase in intragastric pressure.

Third, it is important to remember that there is a possibility that the insufflation gas leaked into the abdominal cavity when the PIP, HR, and end-tidal $\mathrm{CO} 2$ (ETCO2) began to rise. In esophageal endoscopy, it is advisable to consider the possibility of subcutaneous emphysema, pneumothorax, or mediastinal emphysema when PIP, HR, and ETCO2 are elevated.

\section{Conclusion}

We experienced a case of circulatory and respiratory depression during ESD under general anesthesia due to pneumoperitoneum possibly caused by insufflation gas leakage in a PEG patient. Clinicians have to keep in mind the possibility of insufflation gas leakage when performing surgical procedures in PEG patients.

\section{Abbreviations}

CO2: Carbon dioxide; CT: Computed tomography; ESD: Endoscopic submucosal dissection; ETCO2: End tidal carbon dioxide; HR: Heart rate; SpO2: Peripheral oxygen saturation; PEG: Percutaneous endoscopic gastrostomy; PIP: Peak inspiratory pressure; $V C V$ : Volume-controlled ventilation.

\section{Acknowledgements}

The authors would like to thank the Scientific English Editing Section of Fukushima Medical University for editing a draft of this manuscript. 


\section{Authors' contributions}

$\mathrm{JH}$ treated the patient and wrote the manuscript. SK and $\mathrm{JH}$ treated the patient. KK, SO, and SI helped to design the case report. All authors reviewed and approved the final draft.

\section{Funding}

Not applicable.

\section{Availability of data and materials}

Not applicable.

\section{Declarations}

\section{Ethics approval and consent to participate}

Our institution does not require ethical approval for reporting individual case.

\section{Consent for publication}

We obtained written informed consent from the patient to present this case.

\section{Competing interests}

The authors declare that they have no competing interests.

\section{Author details}

1 Department of Anesthesiology, Fukushima Medical University Hospital, 1 Hikarigaoka, Fukushima 960-1295, Japan. ${ }^{2}$ Surgical Operation Department, Fukushima Medical University Hospital, 1 Hikarigaoka, Fukushima 960-1295, Japan.

Received: 14 October 2021 Revised: 20 December 2021 Accepted: 24 December 2021

Published online: 08 January 2022

\section{References}

1. Ari J, Wiesen KS, Fernandes A, Hines J, Indaram A, Weinstein L, et al. True incidence and clinical significance of pneumoperitoneum after PEG placement: a prospective study. Gastrointest Endosc. 2006;64:886-9.

2. Schrag SP, Sharma R, Jaik NP, Seamon MJ, Lukaszczyk JJ, Martin ND, et al. Complications related to percutaneous endoscopic gastrostomy (PEG) tubes. A comprehensive clinical review. J Gastrointestin Liver Dis. 2007;16:407-18.

3. Yalin I, Bora K, Yetkin O, Birol A, Yesim A, Kemal M. Pneumoperitoneum with subcutaneous emphysema after percutaneous endoscopic gastrostomy. Case Rep Surg. 2014;2014:726878.

4. Roviaro GC, Maciocco M, Rebuffat C, Varoli F, Vergani V, Rabughino G, et al. Complications following cholecystectomy. J R Coll Surg Edinb. 1997:42:324-8.

5. Gabbott DA, Dunkley AB, Roberts FL. Carbon dioxide pneumothorax occurring during laparoscopic cholecystectomy. Anaesthesia. 1992 Jul:47(7):587-8.

6. Douglas E. Ott, Subcutaneous emphysema-beyond the pneumoperitoneum. JSLS. 2014;18(1):1-7.

\section{Publisher's Note}

Springer Nature remains neutral with regard to jurisdictional claims in published maps and institutional affiliations.

\section{Submit your manuscript to a SpringerOpen ${ }^{\circ}$ journal and benefit from:}

- Convenient online submission

- Rigorous peer review

- Open access: articles freely available online

- High visibility within the field

- Retaining the copyright to your article

Submit your next manuscript at $\boldsymbol{\nabla}$ springeropen.com 